năng các tạng. Thương tổn lan rộng, kéo dài, khó hồi phục, đặt ra một thách thức lớn cho việc điều trị. Các nghiên cứu khác cũng chỉ ra các vấn đề tương tự $[1,4,6]$.

Về điêu trị, kết quả ghi nhận 27/37 (73\%) bệnh nhân phải thực hiện phẫu thuật cắt cụt trực tràng hay phẫu thuật Hartmann. Có 6 bệnh nhẩn $(16,2 \%)$ phải chịu phẫu thuật cả 3 tạng trực tràng, bàng quang, tử cung và phải mang hậu môn nhân tạo tạm thời hoặc vĩnh viễn cho thấy xạ trị gây những hậu quả khá nghiêm trọng cho người bệnh.

Về phương diện phẫu thuật, đây là phẫu thuật đa tạng, tổ chức xơ sẹo, khó liền sẹo sau mổ, trên cơ địa người bệnh suy kiệt kéo dài, nên vấn đề đánh giá đầy đủ hệ thống phải được đăt ra và giải quyết triệt để. Bên cạnh việc chẩn đoán, giải quyết các biến chứng còn phải đánh giá tình trạng bệnh ung thư cổ tử cung. Kết quả nghiên cứu cho thấy 37 bệnh nhân tai thười điểm phẫu thuật không có ung thư tái phát, hâuu phẫu diễn biến thuận lợi, không có tai biến và biến chứng nặng sau mổ.

Kết quả lâu dài, 7 bệnh nhân (19\%), chết do ung thư tái phát, di căn. Các trường hợp còn sống, sinh hoạt và hòa nhập công việc xã hội tương đối tốt. Không còn triệu chứng chảy máu tiêu hóa. Chức năng hệ tiết niệu ổn định, hài lòng sau phẫu thuật. Nghiên cứu khác cũng cho kết quả tương tự $[1,2]$.

\section{KẾT LUẬN}

Xạ trị ung thư cổ tử cung còn có những biến chứng nặng nề cho các tạng và cấu trúc giải phẫu lân cận. Một số cần can thiệp phẫu thuật, chỉ định chủ yếu do viêm trực tràng chảy máu $(51,4 \%)$, rò phân vào âm đạo, bàng quang (43,2\%).

Kết quả phẫu thuật tốt, không có tai biến, biến chứng nặng sau mổ. Kết quả lâu dài, nguyên nhân tử vong do ung thư tái phát, di căn.

\section{TÀI LIÊU THAM KHẢO}

1. Nguyễn Xuân Hùng (2009) Kết quả điều trị rò trực tràng - âm đạo, tạp chí ngoại khoa số1; 4: tr. $26-29$.

2. Nguyển Văn Tuyên (2008) Nghiên cứu điều trị ung thư cổ tử cung giai đoạn IB-II bằng phương phảp phẫu thuật kết hợp với xạ trị", Luận án tiến sỹ y học, Trường Đại học Y Hà Nội, tr.133̇-134.

3. Small W Jr, Bacon MA, Bajaj A, et al (2017) Cervical cancer: a global health crisis. Cancer 123:2404-12

4. Yang, Jian PhDa; Cai, Haoyang PhDa; Xiao, Zhi-Xiong $\mathrm{PhD}^{\mathrm{a}}$; Wang, Hangyu $\mathrm{MD}^{\mathrm{b}_{*} ;}$; Yang, Ping MDc . (2019) Effect of radiotherapy on the survival of cervical cancer patients volum 98- issue - p e16421

5. Shi D, Liang Z, Zhang C, et al, (2018) The effect of surgery on the survival status of patients with locally advanced cervical cancer after radiotherapy/chemoradiotherapy: a meta-analysis. BMC Cancer ; 18:308.

6. Ghabuous Á et al. (2013) Time course of late rectal- and urinary bladder side effects after MRIguided adaptive brachytherapy for cervical cancer". 535-40 Boni A.

\title{
MÔ TẢ HÀNH VI TỰ CHĂM SÓC CỦA NGƯỜI BỆNH SUY TIM DO TĂNG HUYẾT ÁP TẠI TRUNG TÂM TIM MACH BÊ̂NH VIÊ̂N ĐA KHOA TỈNH HẢI DƯƠNG
} Bùi Thị Hậu*, Nguyễn Thị Lan Anh**,
Đồ Thị Thu Hiền*, Đàm Văn Đạt*

\section{TÓM TẮT}

Với muc tiêu mô tả hành vi tư chăm sóc của người bệnh suy tim do THA và tìm hiểu một số yếu tỗ liênn quan đến hành vi tư chăm sóc của người bệnh suy tim do THA tại Trung tâm Tim mạch Bệnh viện Đa khoa tỉnh Hải Dương từ tháng 08/2020 đển tháng 04 /2021. Qua nghiên cứu cắt ngang 121 người bệnh suy

\footnotetext{
*Trường đại học kỹ thuật Y tế Hải Dương.

**Trướng đai hoc Y Hà Nôi

Chịu trách nhiệm chính: Bùi Thị Hậu

Email: hauhmtu1991@gmail.com

Ngày nhận bài: 22.6.2021

Ngày phản biên khoa hoc: 17.8.2021

Ngày duyệt bài: 24.8.2021
}

tim do tăng huyết áp tại Trung tâm Tim mach Bênh viện Đa khoa tỉnh Hải Dương. Kết quả cho thấy: Người bệnh từ 60 tuổi trở lên chiếm tỷ lệ 91,7\%. Điểm trung bình đạt cao nhất ở chỉ số duy trì tự chăm sóc $(24,02 \pm 7,368)$, thấp nhất ở chỉ số tự tin tự chăm sóc $(16,22 \pm 5,108)$. Điểm kiến thức về bênh suy tim 6,39 $\pm 1,519$. Điểm kiến thức theo dõi huyết áp 11,42 $\pm 1,025$. Điểm hố trơ xã hôi $55,49 \pm 18,766$. Có mối tương quan thuận giữa điểm kiến thức suy tim, điểm kiến thức theo dõi huyết áp, điểm hỗ trơ xã hôi với quản lý tự chăm sóc, duy trì tự chăm sóc, tự tin tự chăm sóc (hêe số tương quan rho $>0,5, p<0,001$ ). Có sự khác biệt giữa nhóm nam giới và nữ giới về điểm hành vi tư chăm sóc bản thân với $p<0,001$. Điểm trung bình duy tự chăm sóc của 2 nhóm phân độ HA bình thường cao và độ I với nhóm phân độ HA độ II 
có sự khác biệt và sự khác biệt này cũng có ý nghĩa với 2 nhóm phân độ suy tim I và II với nhóm phân độ suy tim III và IV (p lần lượt là 0,01 và 0,046 )

\section{SUMMARY \\ DESCRIPTION OF SOLID CARE ACTIONS OF PEOPLE WITH HIGH BLOOD PRESSURE AT HAI DUONG DISEASE HEALTH CENTER IN HAI DUONG PROVINCE}

Objective: Describe self-care behavior of patients with heart failure caused by hypertension at the Heart Center of Hai Duong General Hospital from August 2020 to April 2021. Find out about some factors related to self-care behavior of patients with heart failure caused by hypertension at the Heart Center of Hai Duong General Hospital. Methods: Crosssectional study on 121 patients at Hai Duong General Hospital. Results: The proportion of patients aged 60 and over accounts for $91,7 \%$. Average score was the highest in the self-care maintenance index $(24,02 \pm$ $7,368)$, and the lowest in the self-care index $(16,22 \pm$ $5,108)$. Knowledge score for heart failure $6,39 \pm$ 1,519 . Knowledge score on blood pressure monitoring $11,42 \pm 1,025$. Social support score 55,49 $\pm 18,766$. Conclusion: With a score of $0-100$ points, care practice scores of patients with heart failure due to hypertension in all 3 areas (maintenance of self-care, self-care management, self-care confidence) are low with the real average scores for each area respectively: $24,02 \pm 7,368,17,73 \pm 6,08,16,22 \pm$ 5,108 points. There is a strong and positive correlation between heart failure knowledge score, blood pressure monitoring knowledge score, social support score with self-care management, maintenance of self-care, selfcare confidence correlation coefficient (rho> 0,5, p $<0,001)$. There is a difference between the group of men and women with the self-care behavior score with $p=0,007$. The mean self-care score of the 2 groups of high normal BP and grade I with the BP grade group of grade 1 II has a difference, and this difference is also significant with 2 groups of heart failure class I and II with heart failure class III and IV (with $\mathrm{p}$ is 0,01 , respectively; 0,046 )

\section{I. ĐĂT VẤN ĐỀ}

Suy tim là một trong những bênh lý tim mach có tỷ lệ mắc tăng lên theo tuổi trển toàn thế giới. Suy tim ảnh hưởng sức khỏe của $6-10 \%$ người trên 65 tuổi, là nguyên nhân chính khiến cho người già mắc suy tim phải nằm viện và tái nhập viện. Tăng huyết áp là một trong những nguyển nhân hàng đầu dần đến suy tim trên thế giới cũng như Việt Nam. Theo nghiên cứu thuần tập Framingham có $91 \%$ tổng số bệnh nhân suy tim mới được chẩn đoán trong thời gian theo dõi lên đến 20 năm có liên quan đến tăng huyết áp.

Tư chăm sóc trong bênh suy tim là các hành vi mà người bênh thực hiên để duy trì tình trang thể chất, theo dõi dấu hiệu bệnh, nhận biết và có cách xử lý phù hợp trước những biển đổi hay xuất hiện các triệu chứng của suy tim, đồng thời đánh giá hiệu quả của cách xử lý đó. Bên cạnh đó, sự phức tạp trong chế độ điều trị bệnh suy tim và nhiêu bềnh lý kèm theo ở phần lớn người già mắc suy tim cũng làm cho vấn đề tuân thủ trở nên khó khăn hơn. Với khả năng tự chăm sóc bản thân thấp như việc không tuân thủ chế độ dùng thuốc và khó thay đổi lối sống khi mắc suy tim ở người già sẽ dẫn đến 20 - 60\% người bệnh suy tim phải tái nhập viện và tỷ lệ tử vong còn ở mức cao. Ở Việt Nam đã có một số nghiên cứu về hành vi tự chăm sóc của người bệnh suy tim, tuy nhiên ở Hải Dương, nghiên cứu về vấn đề này còn ít. Nhằm góp phần nâng cao chất lượng chăm sóc cho người bệnh suy tim, chúng tôi tiến hành nghiên cứu đề tài "Nghiên cứu hành vi tư chăm sóc của người bệnh suy tim do tăng huyết áp tại Trung tâm Tim mạch Bệnh viện Đa khoa tỉnh Hải Dương" với muc tiêu:

1. Mô tả hành vi tự chăm sóc của người bênh suy tim do tăng huyêt áp tại Trung tâm Tim mạch Bệnh viện Đa khoa tỉnh Hải Dương tư" tháng 08/2020 đến tháng 04/2021.

2. Tìm hiêu một số yếu tố liên quan đên hành vi tư chăm sóc của người bệnh suy tim do tăng huyết áp tại Trung tâm Tim mạch Bệnh viện Đa khoa tỉnh Hải Dương.

\section{II. ĐỐI TƯỢNG VÀ PHƯƠNG PHÁP NGHIÊN CỨU \\ 2.1. Địa điểm và thời gian nghiên cứu \\ - Địa điểm nghiên cứu: Trung tâm Tim} mạch Bệnh viện Đa khoa tỉnh Hải Dương.

- Thời gian nghiên cứu: từ tháng 08/2020 đến tháng 04/2021

2.2. Đối tượng nghiên cứu. Người bệnh suy tim do THA điều trị tại Trung tâm Tim mạch Bệnh viện Đa khoa tỉnh Hải Dương từ tháng 08/2020 đến tháng 04/2021.

- Tiêu chuẩn lựa chọn: Người bệnh $\geq 18$ tuổi, được chẩn đoán suy tim do THA theo tiêu chuẩn chẩn đoán (phân độ suy tim theo NYHA; phân độ THA theo hội Tim mạch học Việt Nam).

- Tiểu chuẩn loại trừ: Người bệnh chờ phẫu thuật, người bệnh ung thư, phụ nữ có thai; Người bệnh khổng có khả năng tự chăm sóc, phụ thuộc hoàn toàn vào người thân: hôn mê, liệt vận động; Người bệnh có rối loạn về tâm thần, nhận thức, quá già yếu, suy giảm trí nhớ, nhân thức kém... không đủ khả năng nhân thức; Người bệnh không trả lời hết các câu hỏi của bộ công cụ nghiên cứu; Người bệnh không đồng ý tham gia.

\subsection{Phương pháp nghiên cứu}

- Thiết kế nghiên cứu: Nghiên cứu mô tả cắt ngang. 
- Cõ̃ mẫu và phương pháp chọn mẫu: Cõ mẫu được lấy dựa trên sự thuận lợi, dựa trên tính dễ tiếp cận của đối tượng nghiên cứu, phù hợp với tiêu chuẩn lựa chọn .

- Bộ công cụ thu thập số liệu:

+ Bộ thông tin cơ bản và bệnh: gồm các thông tin về tuổi, giới,tình trạng hổn nhân, trình độ học vấn, nghề nghiệp, thu nhập trung bình và các thông tin về bênh kèm theo.

+Bộ câu hỏi về hành vi tự chăm sóc (Self - care of heart failure index (SCHFI)). Thang đo SCHFI v 6.2, được phát triển tại Hoa Kỳ được kiểm định độ tin cậy với hệ số Cronbach alpha đạt 0,80 . Thang đo và cách đánh giá: Gồm 22 câu hỏi chia làm 3 lĩnh vực: duy trì chăm sóc (10 câu), quản lý chăm sóc (6 câu) và sự tự tin (6 câu). Số điểm mỗi hành vi phụ thuộc vào sự lựa chọn của người bệnh với điểm cao nhất là 4. Mỗi lính vực thực hành tự chăm sóc (duy trì chăm sóc, quản lý chăm sóc và sự tự tin) được tính riêng với phổ điểm từ $0-100$. Phẩn loại thực hành: $\geq 70$ điểm: Thực hành tự chăm sóc đạt; < 70 điểm: Thực hành tự chăm sóc không đạt.

+Bô câu hỏi về sự hố trợ xã hội (The Multidimensional Scale of Perceived Social Support (MSPSS)) được phát triển bởi tác giả Zimet (1988) được kiểm định độ tin cậy với hệ số Cronbach alpha 0,76 với mục tiêu để đo lường sự nhận thức về sự hỗ trợ xã hội. Bộ câu hỏi này gồm 12 câu hỏi với 3 nhóm về hỗ trợ xã hội (1) người thân (4 câu hỏi), (2) Gia đình (4 câu hỏi), và (3) Bạn bè (4 câu hỏi). Mỗi câu hỏi có 7 phương án trả lời từ 1 " rất đồng ý" đến 7 " rất không đồng ý". Tổng điểm của sự hỗ trợ xã hội từ 1-7. Người bệnh có tổng điểm cao là người nhận được nhiều sự hỗ trơ xã hội.

+ Bộ câu hỏi về kiến thức suy tim: (The Dutch Heart Failure Knowledge (DHFKS) được phát triển bởi tác giả Vander Wal (2005) được kiểm định độ tin cậy với hệ số Cronbach alpha 0,74 gồm 15 câu hỏi và nhiều lựa chọn được chia làm 3 nhóm: (1) 4 câu hỏi về thông tin chung về suy tim, (2) 6 câu hỏi đánh giá về chế độ ăn, giới hạn và các hành động để đánh giá điêu trị suy tim và (3) 5 câu hỏi đánh giá triệu chứng và sự phát hiện triệu chứng của suy tim. Mối câu hỏi người bênh được 1 điểm cho câu trả lời đúng và nhận điểm 0 cho lựa chọn câu trả lời sai. Tổng số điểm bộ câu hỏi này là $0-15$ điểm. Người bệnh suy tim có tổng điểm cao cho thấy ho có kiển thức tốt về bênh suy tim.

+ Bộ câu hỏi về kiến thức Mức độ Tăng huyết áp (HK-LS) The Hypertension Knowledgelevel Scale của Sultan Baliz
Erkoc và CS (2012) là thang đo đầu tiên sẽ được sử dụng trong các nghiên cứu để ngăn ngửa tăng huyết áptrong tương lai, cũng như cho các chương trình kiểm soát và can thiệp giáo dục để xác định mức độ hiểu biết về tăng huyết áp của người lớn Thổ Nhĩ Kỳ. Hệ số Cronbach alpha cho HK-LS là 0,82 cho toàn bộ thang đo và cao hơn 0,70 cho tất cả các câu hỏi từng mục.Thang đo Kiến thức Mức độ Tăng huyết áp (HK-LS) có 22 mục. Mỗi câu trả lời đúng có giá trị 1 điểm. Điểm tối đa là 22 cho toàn bộ thang điểm, 2 cho "định nghĩa", 4 cho "điều trị y tế", 4 cho "tuân thủ thuốc", 5 cho "lối sống", 2 cho "chế độ ăn uống" và 5 cho phụ "biến chứng" kích thước. Điểm tối thiểu là 0 cho toàn bộ thang đo và cho tất cả các câu hỏi từng mục.

- Phương pháp phân tích và xử lý số liệu: Phương pháp mô tả đã được sử dụng để mô tả về thông tin cơ bản nhất và mức độ hành vi tự chăm sóc bản thân. Mối liên quan giữa các biến và hành vi tự chăm sóc được sử dụng kiểm định test Mann - Whitney, kiểm định test Kruskal - Wallis $\mathrm{H}$, test Kolomogorov- Smimov, Spearman Coreelation coeficient với độ tin cậy 0,05 và SPSS 26 để phân tích số liệu.

- Vấn đề đạo đức nghiên cứu. Nghiên cứu được thông qua bởi Hội đồng Khoa học, Hội đồng Đạo đức của Trường Đại học $Y$ Hà Nội và Trường Đaai học Kỹ thuâtt $Y$ tế Hải Dương, được sự đồng ý của Bệnh viện Đa khoa tỉnh Hải Đương và đồng thuận của Trung tâm Tim mạch. Người bênh tự nguyên tham gia, thông tin cá nhân của người bệnh được giữ bí mật và chỉ phục vụ cho mục đích nghiên cứu và nâng cao chất lượng chăm sóc người bệnh.

\section{KẾT QUẢ NGHIÊN CứU}

Bảng 1: Đăc điểm chung của người bệnh suy tim do THA

\begin{tabular}{|c|c|c|}
\hline $\begin{array}{l}\text { Đặc điếm chung của } \\
\text { người bệnh }\end{array}$ & $\begin{array}{l}\text { Số lượng } \\
(n=121)\end{array}$ & $\begin{array}{l}\text { Tỷ lệ } \\
(\%)\end{array}$ \\
\hline $\begin{aligned} \text { Tuối: } & <60 \text { tuối } \\
& \geq 60 \text { tuổi }\end{aligned}$ & $\begin{array}{c}10 \\
111\end{array}$ & $\begin{array}{c}8,3 \\
91,7\end{array}$ \\
\hline $\begin{array}{ll}\text { Giới: } & \text { Nam } \\
N \tilde{N}\end{array}$ & $\begin{array}{l}50 \\
71\end{array}$ & $\begin{array}{l}41,3 \\
58,7\end{array}$ \\
\hline $\begin{array}{c}\text { Tình trạng hôn nhân } \\
\text { Độc thân } \\
\text { Ly hôn } \\
\text { Kết hôn }\end{array}$ & $\begin{array}{l}13 \\
18 \\
90\end{array}$ & $\begin{array}{c}11 \\
14,8 \\
74,2\end{array}$ \\
\hline $\begin{array}{c}\text { Tình trạng học vấn } \\
\text { Tiểu học } \\
\text { THCŚ } \\
\text { THPT trở lên }\end{array}$ & $\begin{array}{l}45 \\
51 \\
25\end{array}$ & $\begin{array}{l}37,1 \\
42,2 \\
20,7\end{array}$ \\
\hline Thu nhập trung & & \\
\hline
\end{tabular}




\begin{tabular}{|c|c|c|}
\hline bình/tháng & 90 & 74,4 \\
Dưới 5 triệu & 25 & 20,7 \\
Tứ 5-10 triệu & 5 & 4,1 \\
$10-15$ triệu & 1 & 0,8 \\
>15 triệu & & \\
\hline Nghề nghiệp & & \\
Làm ruộng & 66 & 55 \\
Công chức, viên chức & 13 & 10,7 \\
Nghỉ hưu & 20 & 16,5 \\
Khác & 22 & 17,8 \\
\hline Số người ở cùng & & \\
trong gia đình & 31 & 25,5 \\
$\leq 2$ người & 90 & 74,5 \\
$\geq 3$ người & & \\
\hline
\end{tabular}

Nhân xét: Tỉ lệ người bệnh nam là 41,3\%,và người bệnh nữ $(58,7 \%)$ với độ tuổi thấp nhất 50 tuổi và cao nhất là 99 tuổi (tuổi trung bình $=$ 74,09); 74,2\% đối tượng nghiên cứu đã lập gia đình. Tỉ lệ người bệnh có trình độ học vấn tiểu học, THCS chiếm cao nhất đạt $79,3 \%$. Hầu hết họ có thu nhập dưới 5 triệu chiếm 74,4\%. Nghề nghiệp chủ yếu là làm ruộng chiếm trên $50 \%$. Số người sinh hoạt cùng họ trển 2 người chiếm $74,5 \%$.

Bảng 2. Đăc điêm bênh suy tim do THA

\begin{tabular}{|c|c|c|}
\hline Đặc điểm bệnh & $\begin{array}{c}\text { Số lướng } \\
(\mathrm{n}=121)\end{array}$ & $\begin{array}{l}\text { Tỷ lệ } \\
(\%)\end{array}$ \\
\hline $\begin{array}{c}\text { Số bệnh đồng mắc } \\
\leq 2 \text { bệnh } \\
\geq 3 \text { bệnh }\end{array}$ & $\begin{array}{l}59 \\
62\end{array}$ & $\begin{array}{l}48 \\
52\end{array}$ \\
\hline $\begin{array}{c}\text { Mức độ hạn chế vận } \\
\text { động } \\
\text { Hạn chế nghiêm trọng } \\
\text { Hạn chế không nghiêm } \\
\text { trọng } \\
\text { Không hạn chễ }\end{array}$ & $\begin{array}{l}21 \\
62 \\
38\end{array}$ & $\begin{array}{l}17,4 \\
51,2 \\
31,4\end{array}$ \\
\hline $\begin{array}{c}\text { Tình trạng sức khỏe tự } \\
\text { đánh giá } \\
\text { Rất kém } \\
\text { Kém } \\
\text { Bình thường } \\
\text { Tốt }\end{array}$ & $\begin{array}{l}16 \\
59 \\
27 \\
19\end{array}$ & $\begin{array}{l}13,2 \\
48,8 \\
22,3 \\
15,7\end{array}$ \\
\hline $\begin{array}{c}\text { Phân độ suy tim } \\
\text { Độ I+ II } \\
\text { Độ III+IV }\end{array}$ & $\begin{array}{l}54 \\
67\end{array}$ & $\begin{array}{l}45 \\
55\end{array}$ \\
\hline $\begin{array}{c}\text { Phân độ tăng huyết áp } \\
\text { Bình thường cao + Độ I } \\
\text { Độ II }\end{array}$ & $\begin{array}{l}52 \\
69\end{array}$ & $\begin{array}{l}43 \\
57\end{array}$ \\
\hline
\end{tabular}

Nhân xét: Số bệnh đồng mắc chủ yếu là trên 3 bệnh chiếm trên $50 \%$. Tỉ lệ cao nhất $(51,2$ \%) người bệnh có mức độ hạn chế vận động ở mức không nghiêm trọng. Đa số đối tượng nghiên cứu $(48,8 \%)$ tự đánh giá mình sức khỏe ở mức kém. Khoảng 55\% đối tượng nghiên cứu có phân độ suy tim mức III và độ IV và chủ yếu ở mức phân độ THA độ II.

Bảng 3. Tì lệ người suy tim do THA có khả năng tự chăm sóc phù hợp

\begin{tabular}{|c|c|c|}
\hline Phân loại & $\begin{array}{c}\text { Số lượng } \\
\text { (n) }\end{array}$ & $\begin{array}{c}\text { Tỷ lệ } \\
(\mathbf{\%})\end{array}$ \\
\hline Quản lý tự chăm sóc $(\geq 70)$ & 15 & 12,3 \\
\hline Duy trì tự chăm sóc $(\geq 70)$ & 26 & 21,4 \\
\hline Tự tin tự chăm sóc $(\geq 70)$ & 33 & 27,3 \\
\hline
\end{tabular}

Nhân xét: Người bênh có khả năng quản lý tự chăm sóc là $12,3 \%$; người bệnh có khả năng duy trì tự chăm sóc là $21,4 \%$,người bệnh đạt tự tin chăm sóc là $27,3 \%$.

Bảng 4. Điếm trung bình hành vi tưr chăm sóc của người bệnh suy tim do THA

\begin{tabular}{|c|c|}
\hline $\begin{array}{c}\text { Điểm trung bình hành vi } \\
\text { tự chăm sóc }\end{array}$ & $\begin{array}{c}\text { Median } \mathbf{~} \\
\text { rank }\end{array}$ \\
\hline $\begin{array}{c}\text { Điểm trung bình khả năng } \\
\text { duy trì chăm sóc }\end{array}$ & $24,14 \pm 7,905$ \\
\hline $\begin{array}{c}\text { Điểm trung bình khả năng } \\
\text { quản lý chăm sóc }\end{array}$ & $14,69 \pm 4,334$ \\
\hline $\begin{array}{c}\text { Điểm trung bình khả năng tự } \\
\text { tin chăm sóc }\end{array}$ & $15,46 \pm 4,891$ \\
\hline
\end{tabular}

Bảng 5. Điểm trung binh kiến thức suy tim, kiến thức theo dối $H A$, diểm hố trợ nhận thức xã hội

\begin{tabular}{|c|c|}
\hline Thang điểm & $\mathbf{X} \pm$ SD \\
\hline Điểm kiến thức suy tim & $6,39 \pm 1,519$ \\
\hline Điểm kiến thức theo dõi HA & $11,42 \pm 1,025$ \\
\hline Điểm hỗ trợ nhận thức xã hội & $55,49 \pm 18,766$ \\
\hline
\end{tabular}

Nhân xét: Người bênh có điểm kiến thức suy tim cao nhất đạt 10 điểm, thấp nhất đạt 2 điểm, điểm trung bình đạt $6,39 \pm 1,519$. Điểm kiến thức theo dõi huyết áp cao nhất đạt 19 điểm, thấp nhất đạt 3 điểm, điểm trung bình đạt 11,42 $\pm 1,025$. Điểm hỗ trợ xã hội cao nhất đạt 90 điểm, thấp nhất 12 điểm, điểm trung bình đạt $55,49 \pm 18,766$.

Bảng 6. Môi liên quan giữa giới tính, phân độ HA, phân độ ST với chi số tự chăm sóc của người bệnh suy tim do THA ( $n=121)$

\begin{tabular}{|c|c|c|c|c|c|c|c|}
\hline \multirow{2}{*}{\begin{tabular}{l|l|} 
Số bênh & Nhóm có số bênh \\
\end{tabular}} & \multirow[b]{2}{*}{$\mathbf{n}$} & \multicolumn{2}{|c|}{$\begin{array}{l}\text { Quản lý tự } \\
\text { chăm sóc }\end{array}$} & \multicolumn{2}{|c|}{\begin{tabular}{|c|}
$\begin{array}{c}\text { Duy trì tứ chăm } \\
\text { sóc }\end{array}$ \\
\end{tabular}} & \multicolumn{2}{|c|}{$\begin{array}{l}\text { Tự tin tứ } \\
\text { chăm sóc }\end{array}$} \\
\hline & & Median & $\mathbf{p}$ & Median & $\mathbf{p}$ & Median & $\mathbf{p}$ \\
\hline \begin{tabular}{c|c|}
$\begin{array}{c}\text { Số bênhh } \\
\text { đhóm cón số bênnh } \\
\text { đồng mắc }<3 \text { bệnh }\end{array}$ \\
\end{tabular} & 59 & 14,0 & $0,640 *$ & 23,0 & $0,251^{*}$ & 14,0 & $0,690 *$ \\
\hline
\end{tabular}


VIETNAM MEDICAL JOURNAL N01 - SEPTEMBER - 2021

\begin{tabular}{|c|c|c|c|c|c|c|c|c|}
\hline mắc & $\begin{array}{l}\text { Nhóm có số bênh } \\
\text { đồng mắc } \geq 3 \text { bệnh }\end{array}$ & 62 & 13,76 & & 21,12 & & 13,2 & \\
\hline \multirow{2}{*}{$\begin{array}{c}\text { Phân độ } \\
\text { THA }\end{array}$} & $\begin{array}{c}\text { Nhóm bình thường } \\
\text { cao + Đô I }\end{array}$ & 52 & 15,0 & \multirow{2}{*}{$0,309 *$} & 26,0 & \multirow{2}{*}{$0,01^{*}$} & 15,0 & \multirow{2}{*}{$0,85^{*}$} \\
\hline & Nhóm Độ II & 69 & 13,0 & & 21,0 & & 14,0 & \\
\hline \multirow{2}{*}{$\begin{array}{l}\text { Phân độ } \\
\text { suy tim }\end{array}$} & Phân độ STं I+II & 54 & 14,0 & \multirow[b]{2}{*}{$0,372 *$} & 24,0 & \multirow[b]{2}{*}{$0,046 *$} & 14,0 & \multirow[b]{2}{*}{$0,933^{*}$} \\
\hline & $\begin{array}{c}\text { Phân độ suy tim } \\
\text { III+IV }\end{array}$ & 67 & 12,47 & & 22,0 & & 13,55 & \\
\hline
\end{tabular}

Nhận xét: Về giới, nhóm nam giới và nữ giới có sự khác biệt với điểm hành vi tự chăm sóc bản thân và sự khác biệt này có ý nghĩa thống kê với giá trị $\mathrm{p}$ tương ứng $\mathrm{p}<0,01$.

Điểm trung bình duy tự chăm sóc của 2 nhóm phân độ $\mathrm{HA}$ bình thường cao và độ I với nhóm phân độ HA độ II có sự khác biệt với điểm duy trì tự chăm sóc của nhóm phẩn độ $\mathrm{HA}$ bình thường cao và độ I cao hơn nhóm phân độ HA

độ II và sự khác biệt này có ý nghĩa thống kê với giá trị $\mathrm{p}$ tương ứng $\mathrm{p}<0,05$.

Điểm trung bình duy tự chăm sóc của 2 nhóm phân độ suy tim I và II với nhóm phân độ suy tim III và IV có sự khác biệt với điểm duy trì tự chăm sóc của nhóm phân độ suy tim I và II cao hơn nhóm phân độ suy tim III và IV. Sự khác biệt này có ý nghĩa thống kê với $p<0,05$.

Bảng 7. Môi liên quan giữa sự hiểu biêt kiến thức suy tim, kiến thức theo dôi HA, sự hố trợ xã hội với khả năng tự chăm sóc của người bệnh suy tim do THA.

\begin{tabular}{|c|c|c|c|c|c|c|}
\hline \multirow{2}{*}{ 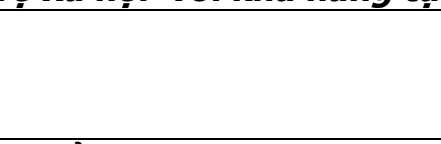 } & \multicolumn{2}{|c|}{$\begin{array}{c}\text { Quản lý tứ chăm } \\
\text { sóc }\end{array}$} & \multicolumn{2}{|c|}{$\begin{array}{c}\text { Duy trì tự chăm } \\
\text { sóc }\end{array}$} & \multicolumn{2}{|c|}{ Tự tin tự chăm sóc } \\
\hline & rho & $p$ & rho & $\mathrm{p}$ & rho & $\mathrm{p}$ \\
\hline Điểm kiến thức suy tim & 0,604 & 0,000 & 0,538 & 0,000 & & 0,000 \\
\hline Điểm kiến theo dõi HA & 0,527 & 0,000 & 0,547 & 0,000 & 0,598 & 0,000 \\
\hline Điểm hố trợ xã hội & 0,683 & 0,000 & 0,668 & 0,000 & 0,568 & 0,000 \\
\hline
\end{tabular}

Nhân xét: Có mối tương quan thuận giữa điểm kiến thức suy tim, điểm kiến thức theo dõi huyết áp, điểm hỗ trợ xã hội với quản lý tự chăm sóc, duy trì tự chăm sóc, tự tin tự chăm sóc có hệ số tương quan rho $>0,5 ; p<0,001$.

\section{BÀN LUẬN}

1. Mô tả hành vi tự chăm sóc của người bệnh suy tim do THA. Kết quả của nghiên cứu này đã chỉ ra hành vi tự chăm sóc của người bệnh suy tim do THA bao gồm các nội dung liên quan đến quản lý tự chăm sóc, duy trì tự chăm sóc và tự tin tự chăm sóc.Trong đó, có $87,7 \%$ người bệnh suy tim do THA không biết cách quản lý được hành vi tự chăm sóc của mình, có $78,6 \%$ người bệnh có điểm duy trì tự chăm sóc thấp và $72,7 \%$ người bênh có điểm tự tin tự chăm sóc đạt dưới 70 điểm. Kết quả này phù hợp với các nghiên cứu khác đã tìm thấy hành vi tự chăm sóc của người bệnh suy tim do THA vẫn thấp. Hành vi tự chăm sóc của người bệnh suy tim do THA có thể khó bởi các thay đổi về tim mạch, hô hấp, tiêu hóa...Trong nghiên cứu này, hầu hết đối tượng nghiên cứu $(79,3 \%)$ có trình độ học vấn từ THCS trở xuống. Hơn nữa, khi những yếu tố này kết hợp với việc thiếu kiến thức về bệnh, với sự phức tạp của hành vi tự chăm sóc để thành công trong hành vi tự chăm sóc suy tim là rất khó khăn. Hơn nữa, hành vi tự chăm sóc phải được phổ biến, được học và phải tuân thủ liên tục. Đó là lý do tại sao người bênh suy tim do THA không thể thực hiên được hành vi này và có thể làm cho hành vi tự chăm sóc của họ ở mức độ thấp.

2. Các yếu tố liên quan đến hành vi tự chăm sóc của người bênh suy tim do THA. Có sự khác biệt giữa nhóm nam giới và nữ giới với điểm hành vi tự chăm sóc bản thân với $p$ $<0,01$. Điểm trung bình duy tự chăm sóc của 2 nhóm phân đô $\mathrm{HA}$ bình thường cao và độ I với nhóm phân độ HA độ II có sự khác biệt, và sự khác biệt này cũng có ý nghĩa với 2 nhóm phân độ suy tim I và II với nhóm phân độ suy tim III và IV. Với $p$ lần lượt là $0,01 v a ̀$ a,046. Các kết quả trên đều phù hợp với các nghiên cứu của các tác giả Đinh Thị Thuý Hà (năm 2016) tại viện Tim mạch quốc gia, tác giả Nguyễn Ngọc Huyền (2013) tại BV đa khoa tỉnh Thái Nguyên.

Kiến thức suy tim, kiến thức theo dõi $H A$, điểm hỗ trợ xã hội liên quan đên hành vi tự chăm sóc bản thân với rho lần lượt là 0,064 ; 0,$527 ; 0,638$. Kiến thức suy tim là yếu tố quan trọng liên quan đến sự tuân thủ các hành vi tự chăm sóc ở người bệnh suy tim do THA. Trong 
nghiên cứu này, kiến thức suy tim ảnh hưởng trực tiếp tới hành vi tự chăm sóc bản thân được chỉ rõ và là yếu tố cần thiết để thực hiện hành vi này. Kết quả này phù hợp với nhiều nghiên cứu khác. Thực tế trên cũng phản ánh troog nghiên cứu của chúng tôi, đa số người tham gia nghiên cứu đến từ các vùng nông thôn, thu nhập bình quân $<5$ triệu /tháng chiếm $74,4 \%$, trình độ học vấn thấp chủ yếu là từ THCS trở xuống $(79,3$ \%) nên kiến thức hiểu biết về bệnh tăng huyết áp còn thấp, chưa được kiểm soát chặt chẽ dẫn tới chất lượng điều trị đạt hiệu quả chưa cao. Đồng thời, nghiên cứu của Gallader và cộng sự (2011) và Sayer và cộng sự (2008) chỉ ra rằng sự hỗ trợ xã hội có liên quan đến hành vi tự chăm sóc bản thân ở người bệnh suy tim. Một lý do có thể giải thích được là do văn hóa người Việt Nam từ xưa đến nay theo truyền thống gia đình có nhiều thế hệ, khuyến khích thành viên trẻ trong gia đình chăm sóc người thân khi họ đau ốm, nằm viện. Điều đó phù hợp với 74,5 \% đối tượng trong nghiên cứu này sống chung với các con cái trong gia đình.

\section{KẾT LUÂN}

1. Mô tả hành vi tự chăm sóc của người bệnh suy tim do THA.

- Điểm quản lý tự chăm sóc của người bệnh suy tim do THA đạt $17,73 \pm 6,084$, điểm tự tin tự chăm sóc $16,22 \pm 5,108$ và điểm duy trì chăm sóc $24,02 \pm 7,368$.

- Người bệnh có điểm kiến thức suy tim cao nhất đạt 10 điểm, thấp nhất đạt 2 điểm, điểm trung bình đạt $6,39 \pm 1,519$.

- Điểm kiến thức theo dõi huyết áp thường xuyên của người bệnh suy tim do tăng huyết áp trung bình đạt $11,42 \pm 1,025$, cao nhất đạt 19 điểm, thấp nhất đạt 3 điểm.

- Điểm hỗ trợ xã hội cao nhất đạt 90 điểm, thấp nhất 12 điểm, điểm trung bình đạt $(55,49 \pm$ 18,766).

2. Một số yếu tố liên quan đến hành vi tự chăm sóc của người bệnh suy tim do THA.

* Có mối tương quan thuận và mạnh giữa điểm kiến thức suy tim, điểm kiến thức theo dõi huyết áp, điểm hỗ trợ xã hội với quản lý tự chăm sóc, duy trì tự chăm sóc, tự tin tự chăm sóc có hệ số tương quan rho $>0,5, p<0,001$.

* Về giới, nhóm nam giới và nữ giới có sự khác biệt với điểm hành vi tự chăm sóc bản thân và sự khác biệt này có ý nghĩa thống kê với giá trị $\mathrm{p}$ tương ứng $\mathrm{p}=0,007<0,01$
Điểm trung bình duy tự chăm sóc của 2 nhóm phân độ $\mathrm{HA}$ bình thường cao và độ I với nhóm phân độ HA độ II có sự khác biệt với điểm duy trì tự chăm sóc của nhóm phân độ $\mathrm{HA}$ bình thường cao và độ I cao hơn nhóm phân độ HA độ II và sự khác biệt này có ý nghĩa thống kề với giá trị $\mathrm{p}$ tương ứng $\mathrm{p}=0,01<0,05$.

* Điểm trung bình duy tự chăm sóc của 2 nhóm phân độ suy tim I và II với nhóm phân độ suy tim III và IV có sự khác biệt với điểm duy trì tự chăm sóc của nhóm phân độ suy tim I và II cao hơn nhóm phân độ suy tim III và IV. Sự khác biệt này có ý nghĩa thống kê với $p=0,046$ $<0,05$.

\section{TÀI LIÊU THAM KHẢO}

1. Yancy Clyde W. et al. (2013), "2013 ACCF/AHA Guideline for the Management of Heart Failure", Circulation, 128(16), pp. e240-e327.

2. Benjamin Emelia J. et al. (2019), "Heart Disease and Stroke Statistics-2019 Update: A Report From the American Heart Association", Circulation, 139(10), pp. e56-e528.

3. Carlson B., Riegel B., Moser D. K. (2001), "Self-care abilities of patients with heart failure", Heart Lung, 30(5), pp. 351-9.

4. Miller C. A. (2009), Nursing for wellness in older adults. Wolters Kluwer Health/Lippincott Williams \& Wilkins, Philadelphia.

5. Van der Wal M. H., Jaarsma T. (2008), "Adherence in heart failure in the elderly: problem and possible solutions", Int J Cardiol, 125(2), pp. 203-8.

6. Moser D. K., Watkins J. F. (2008), "Conceptualizing self-care in heart failure: a life course model of patient characteristics", J Cardiovasc Nurs, 23(3), pp. 205-18; quiz 219-20.

7. Trân Thị Ngọc Anh (2016). Kiến thức và thực hành tự chăm sóc ở nhà của người bệnh suy tim mạn tính tại viện Tim Mạch Việt Nam, Luận văn thạc sỹ y học, Trường Đại học Y Hà̀ Nội.

8. Nguyê̂n Ngọc Huyền, Nguyển Tiến Dũng (2013), "Cac yếu tố liến quan đến hành vi tự chăm sóc của người già suy tim tại Bệnh viện Đà khoa Trung ương Thái Nguyên", Tạp chí Tim mạch hoc Việt Nam, 64, pp. 26-33.

9. Hoàng Thi Mính Thái (2016). Kiến thức tư chăm sóc và một số yếu tố liên quan của người cao tuổi tăng huyết áp điêuu trị ngoại trú tại bệnh viện đa khoa tỉnh Nam Định năm 2016,Luận văn thạc sỹ y học, Trường Đại học Điêuu Dưỡng Nam Định.

10. Vasan RS, Levy D. The role of hypertension in the pathogenesis of heart failure. Overview of clinical mechanics. Arch Intern Med 1996; 156: 1789-1796.

11. Travers B. et al. (2007), "Fluid restriction in the management of decompensated heart failure: no impact on time to clinical stability", J Card Fail, 13(2), pp. 128-32. 